\title{
EMLA- AN EFFECTIVE TOOL FOR TOPICAL ANALGESIA IN SPLIT SKIN GRAFT HARVEST
}

\section{Lalit Agrawal}

\section{Fahud Khurram}

(DNB General Surgery) Mch plastic surgery resident, Department of plastic surgery, Jawaharlal Nehru medical college and hospital, Aligarh (Uttar Pradesh) India

(Mch Plastic Surgery) Associate professor, Department of plastic surgery, Jawaharlal Nehru medical college and hospital, Aligarh (uttarpradesh). India

(MS General Surgery), Mch plastic surgery resident, Department of plastic surgery, Jawaharlal Nehru medical college and hospital, Aligarh (uttar pradesh) India *Corresponding Author

ABSTRACT Background: Many patients require general anesthesia merely for skin grafting. EML.A cream which is a eutectic mixture of Lignocaine and Prilocaine provides surface anesthesia when applied on intact skin. Its role in venepuncture or IV cannula insertion in children is well documented.

Aim and Objective: To compare effectiveness of EMLA over infiltrative local anaesthesia in split skin graft harvest.

Method: A prospective study was conducted on 64 patients who required skin grafting. Various indications for grafting were noted. The patients were randomly allocated to two groups. In one group 32 patients, graft was harvested after application of EMLA cream whereas in another group of 32 patients, graft was harvested by infiltrating local anesthesia. Pain perceived during donor area preparation, graft harvesting and post-operative pain was recorded and compared between the two groups on Visual analogue scale and Likert scale.

Results: Total 64 patients were included in the study with 32 patients in either group. Traumatic loss of skin was the most common indication in either group for skin graft harvest. As per visual analogue scale during the graft harvest, most of the patients were in the range of $4-7$ score in either group (71.87\% vs $53.12 \%$ ). $75 \%$ of the patients were in the $4-7$ score in both groups. As per likert scale during the graft harvest score of 4 was noted in $62.5 \%$ in group l vs $53.12 \%$ in group 2 patients. $81.25 \%$ patients in group 1 reported procedure as excellent versus $53.12 \%$ patients in group 2. Patients experienced more pain during infiltration of local anesthesia. Whereas more bleeding was noted in EMLA group immediately after harvest of graft.

Conclusions: EMLA cream can be effectively used as an alternative to local anaesthetic infiltration for harvest of split thickness skin graft.

KEYWORDS : EMLA, Local Infiltration, Pain, Split skin graft

\section{INTRODUCTION:}

Many patients need to undergo general anesthesia solely for skin grafting. However, there are many selected elderly and frail patients in which administering general anesthesia can be hazardous. ${ }^{[1]}$ Graft can be harvested under local anesthesia in patients in which small area needs to be grafted. Injection of local anaesthetic causes pain which can progressively worsen needle anxiety, and can cause tissue oedema leading to distortion of the surgical site. These problems can be overcome with the practical use of topical anaesthetics. However, the skin barrier (stratum corneum) establishes a natural barrier to the penetration of topically applied drugs. ${ }^{[2]}$ The highly lipophilic amino-ester, ketocaine, was introduced in the late 1970s. It was an effective topical anaesthetic for intact skin. However, it caused local toxic reactions on repeated application leading to its withdrawal. ${ }^{[3]}$ EMLA Cream (lidocaine 2.5\% and prilocaine 2.5\%) come by an emulsion in which the oil phase is a Eutectic Mixture of Lidocaine and Prilocaine (EMLA) in a ratio of $1: 1$ by weight. ${ }^{[2]}$ Both local anaesthetics in this eutectic mixture exist in liquid oil form rather than as crystals as they possess a melting point below room temperature. ${ }^{[4]}$ With EMLA, sufficient local anaesthetic diffuses into the superficial layers of the intact skin to produce a clinically valuable effect. Our study was designed to compare the effectiveness of EMLA cream for harvest of skin graft with that of local infiltration of lignocaine and adrenaline.

\section{AIMS AND OBJECTIVE:}

To study effectiveness of EMLA cream as an alternative to local infiltration using lignocaine with adrenaline in harvesting split thickness skin graft.

\section{Objectives:}

1) EMLA cream and local infiltration will be done in the respective groups of patients before split skin graft harvest.

2) To compare both the groups on the basis of discomfort during donor area preparation, pain during graft harvest, intraoperative bleeding from donor area, postoperative discomfort.

\section{MATERIALS AND METHODS:}

Patients requiring grafting to a limited area were treated at the Department of Plastic Surgery at JN Medical college and Hospital, Aligarh (India) between Nov 2017 - Feb 2020 after getting consent from all the patients.

A prospective study was conducted on 64 patients (30 males, 34 females) with ages typically ranging from 20 to 70 years.

\section{Inclusion criteria:}

1) Patients having need of skin grafting to a limited area.

2) Patients willing for the procedure and photographic documentation.

\section{Exclusion criteria:}

1) Known history of allergic hypersensitivity to local ancesthesia

2) Patients with apparent psychiatric conditions and neurological disease and severe co-morbid disease. 
After admission of the patients they were randomly allocated to their groups. The two groups were matched in respect to age, sex, weight and indications for split skin grafting and area which need to be grafted (table 1). The graft was harvested from the thigh area in all the patients. The maximum size of the graft harvested was limited to $100 \mathrm{~cm}^{2}$. The demographic profile and the indications for Skin graft were recorded for each patient. Anti-anxiety drugs (like Diazepam/Alprax) was not given to any patient during the preoperative period. In all the patients EMLA cream as well as local infiltration was done by the operating surgeon.

The donor site was shaved just before the surgery in both the groups in the preoperative room and cleaned with an alcohol swab. Area of skin to be harvested was then marked in size of $100 \mathrm{~cm}^{2}$ (fig 1). Before proceeding with the injection or application of the cream, the procedure was again explained to the patient to decrease the apprehension. Sensitivity testing was carried out for both group of patients before injecting the local anaesthetic and application of cream.

In local anaesthesia infiltration group, combination of lignocaine $0.5 \%$ and adrenaline $1: 200,000$ were administered in subcutaneous tissue with $26 \mathrm{G}$ needle, 7 minutes before harvest of the graft (fig 1). In another treatment group of patients, $20 \mathrm{~g}$ of EMLA cream was applied in a thick layer over marked $100 \mathrm{~cm}^{2}$ area which was evenly spread over the area with the help of spreader provided with the pack. It was finally covered with Opsite occlusive dressing (fig 1). Light bandaging was done over it to hold the dressing in place. The EMLA cream and occlusive dressing were kept in place for 120 minutes. Donor area was massaged through plastic dressing at every 15 minutes intervals to ensure thick, uniform layer of EMLA cream over the entire applied area.

Any pain experienced by the patients during donor area preparation were recorded in both the groups on visual analogue scale. ${ }^{[5]}$ Donor areas were assessed for oedema, redness and paleness in both the groups just before the graft harvest.

Split thickness grafts were harvested using a Humby's grafting handle in all the cases. Bleeding from the donor area was recorded in both groups. The amount of graft harvested was dictated by the area to be grafted with maximum graft harvest limited to less than $100 \mathrm{~cm}^{2}$. Pain experienced during harvest of graft were again recorded using visual analogue scale (VAS).

All the patients who underwent surgery were kept under observation. They were evaluated for post-operative pain, need for analgesia and acceptability/satisfaction after procedure. All the patients were discharged after their first dressing was changed.

Satisfaction of patients was recorded on subjective basis on the scale from excellent to bad with excellent being on higher side and bad on lower side (excellent, very good, good, poor, bad).

Assessment of the patients were done on:

1) Visual analogue scale: Pain was assessed using a simplified version of visual analogue scale.

Patients were asked to indicate on a scale of 0-10 where 0 indicating no pain at all and 10 being the worst pain experienced.

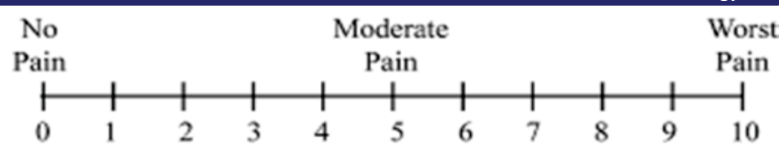

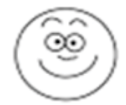

0

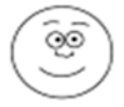

2

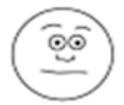

4

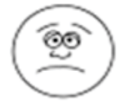

6

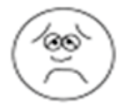

8

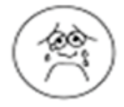

10
2) Likert scale: It is a unidimensional scaling method where the parameters are given values from 1-5. The effectiveness of anaesthesia in either group was scored depending upon the facial expressions and physical response as well as verbal compliant by the patients during the procedure.

The scores and their description is as follows:

Score 1: (Most ineffective) - patient complaint of extreme pain with flaying of extremities, moving head, shouting and treatment could not be completed.

Score 2: (Ineffective) - patient showed expression of pain, verbally conveyed pain by crying. Treatment could not be completed.

Score 3: (Slightly effective) - patient underwent treatment with constant wincing throughout the procedure.

Score 4: (Effective) - patient got the treatment done with occasional episodes of some discomfort.

Score 5: (Very effective) - patient got the treatment done without any indication of pain or discomfort.

\section{RESULTS:}

The 64 patients which were included in the study were equally divided into two treatment groups by random allocation. Both the groups were comparable in terms of age, body weight, size of defect and indications for grafting. Demographics and indications for grafting are described in table $1 \& 2$.

Table 1: Patient Demographics

\begin{tabular}{|l|l|l|}
\hline Demographics & $\begin{array}{l}\text { EMLA Cream } \\
(\mathbf{n}=32)\end{array}$ & $\begin{array}{l}\text { Infiltration group } \\
(\mathbf{n}=32)\end{array}$ \\
\hline Mean Age & 41 Years & 43 Years \\
\hline Male & 16 & 14 \\
\hline Female & 16 & 18 \\
\hline Mean Weight & $56 \mathrm{Kg}$ & $57.5 \mathrm{Kg}$ \\
\hline
\end{tabular}

Table 2: Indications for grafting

\begin{tabular}{|l|l|l|}
\hline Indications for grafting & $\begin{array}{l}\text { EMLA group } \\
(\mathbf{n}=\mathbf{3 2})\end{array}$ & $\begin{array}{l}\text { Infiltration } \\
\text { group }(\mathbf{n}=\mathbf{3 2})\end{array}$ \\
\hline Burn Wounds & 3 & 4 \\
\hline Leg Ulcer & 3 & 3 \\
\hline Traumatic Loss & 15 & 14 \\
\hline Tattoo Excision & 2 & 3 \\
\hline Contracture Release & 4 & 4 \\
\hline Chronic Wound & 3 & 2 \\
\hline Others & 2 & 2 \\
\hline
\end{tabular}

Average total application time for EMLA cream with occlusive dressing was 5 minutes and for infiltration of local anaesthesia was $10 \mathrm{~min}$. The mean waiting period for topical local anaesthesia (EMLA) was 120minutes whereas it was 7 minutes in local infiltration group.

Pain perceived by patients (VAS scores) and effectiveness of anaesthesia (Likert scale) during application or infiltration, 
graft harvest and postoperative period in both the groups is shown in table $3 \& 4$

Table 3: Pain perception scores by the patient (VAS) using EMLĀ and local infiltration

\begin{tabular}{|c|c|c|c|c|c|c|}
\hline & \multicolumn{3}{|c|}{ EMLA $(n=32)$} & \multicolumn{3}{|c|}{$\begin{array}{l}\text { LOCALL INFILTRATION } \\
(\mathrm{n}=32)\end{array}$} \\
\hline & \multicolumn{3}{|c|}{ Visual analogue scale } & \multicolumn{3}{|c|}{ Visual analogue scale } \\
\hline & $0-3$ & $4-7$ & $8-10$ & $0-3$ & $4-7$ & 8-10 \\
\hline $\begin{array}{l}\text { During } \\
\text { application } \\
\text { or infiltration }\end{array}$ & $\begin{array}{l}32 \\
(100 \%)\end{array}$ & - & - & $\begin{array}{l}2 \\
(6.25 \%)\end{array}$ & $\begin{array}{l}25 \\
(78.12 \%)\end{array}$ & $\begin{array}{l}5 \\
(15.62 \%)\end{array}$ \\
\hline $\begin{array}{l}\text { During graft } \\
\text { harvest }\end{array}$ & $\begin{array}{l}5 \\
(15.62 \%)\end{array}$ & $\begin{array}{l}23 \\
(71.87 \%)\end{array}$ & \begin{tabular}{|l|}
4 \\
$(12.5 \%)$
\end{tabular} & $\begin{array}{l}3 \\
(9.37 \%)\end{array}$ & $\begin{array}{l}17 \\
(53.12 \%)\end{array}$ & $\begin{array}{l}12 \\
(37.5 \%)\end{array}$ \\
\hline $\begin{array}{l}\text { Postoperative } \\
\text { period }\end{array}$ & \begin{tabular}{|l}
7 \\
$(21.87 \%)$
\end{tabular} & $\begin{array}{l}24 \\
(75 \%)\end{array}$ & $\begin{array}{l}1 \\
(3.12 \%)\end{array}$ & $\begin{array}{l}5 \\
(15.62 \%)\end{array}$ & $\begin{array}{l}24 \\
(75 \%)\end{array}$ & \begin{tabular}{|l|}
3 \\
$(9.37 \%)$
\end{tabular} \\
\hline
\end{tabular}

Table 4: Effectiveness of anaesthesia by the clinician (Likert scale) using EMLA and local infiltration

\begin{tabular}{|c|c|c|c|c|c|c|c|c|c|c|}
\hline & \multicolumn{5}{|c|}{ EMLA $(n=32)$} & \multicolumn{5}{|c|}{ LOCAL INFILTRATION $(\mathrm{n}=32)$} \\
\hline & \multicolumn{5}{|c|}{ Likert scale } & \multicolumn{5}{|c|}{ Likert scale } \\
\hline & 1 & 2 & 3 & 4 & 5 & 1 & 2 & 3 & 4 & 5 \\
\hline $\begin{array}{l}\text { During } \\
\text { application } \\
\text { or } \\
\text { infiltration }\end{array}$ & - & - & - & - & $\begin{array}{l}32 \\
(100 \\
\%)\end{array}$ & - & - & \begin{tabular}{|l|}
2 \\
$(6.25$ \\
$\%)$
\end{tabular} & \begin{tabular}{|l|}
5 \\
$(15.6$ \\
$2 \%)$
\end{tabular} & \begin{tabular}{|l|}
25 \\
$(78.1$ \\
$2 \%)$
\end{tabular} \\
\hline $\begin{array}{l}\text { During } \\
\text { graft } \\
\text { harvest }\end{array}$ & - & - & \begin{tabular}{|l}
5 \\
$(15.6$ \\
$2 \%)$
\end{tabular} & $\begin{array}{l}20 \\
(62.5 \\
\%)\end{array}$ & \begin{tabular}{|l|}
7 \\
$(21.8$ \\
$7 \%)$ \\
\end{tabular} & - & - & $\begin{array}{l}10 \\
(31.2 \\
5 \%)\end{array}$ & $\begin{array}{l}17 \\
(53.1 \\
2 \%) \\
\end{array}$ & \begin{tabular}{|l}
5 \\
$(15.6$ \\
$2 \%)$
\end{tabular} \\
\hline
\end{tabular}

The side effects at donor sites were examined after taking the graft. Pallor was noticed in 12 patients in EMLA group and in 26 patients of local anaesthesia infiltration group. Bleeding was found to be more in EMLA group as compared to infiltration group (fig 1). No effect on healing of donor area was noticed in either groups.

The main reason behind the patients being less satisfied in infiltrative group was the pain experienced during infiltration of local anaesthesia (table 5).

Table 5: Comparison of overall outcome in both groups

\begin{tabular}{|l|l|l|}
\hline Outcome category & $\begin{array}{l}\text { EMLA group } \\
(\mathbf{n}=32)\end{array}$ & $\begin{array}{l}\text { Local infiltration } \\
\text { group (n=32) }\end{array}$ \\
\hline Excellent & $26(81.25 \%)$ & $17(53.12 \%)$ \\
\hline Very good & $3(9.37 \%)$ & - \\
\hline Good & $1(3.12 \%)$ & $10(31.25 \%)$ \\
\hline Poor & $2(6.25 \%)$ & $5(15.62 \%)$ \\
\hline Bad & $1(3.12 \%)$ & - \\
\hline
\end{tabular}

\section{DISCUSSION:}

EMLA Cream (lidocaine $2.5 \%$ and prilocaine $2.5 \%$ ) is a eutectic mixture of lidocaine and prilocaine in a ratio of $1: 1$ by weight. Each gram of EMLA contains lidocaine $25 \mathrm{mg}$, prilocaine $25 \mathrm{mg}$, Arlatone 289, carboxypolymethylene (as a thickening agent), purified water and sodium hydroxide to $\mathrm{pH}$ 9.2. ${ }^{[6]}$

EMLA causes decrease in perception of normally painful stimuli and suppresses the excitability of cutaneous C receptors. ${ }^{[7]}$ Lidocaine and prilocaine are amide-type local anaesthetic agents. Both lidocaine and prilocaine stabilize neuronal membranes by binding to $\mathrm{Na}^{+}$channel and decreasing uptake of $\mathrm{Na}^{+}$ions into the nerve needed for the initiation and conduction of impulses. ${ }^{[8]}$

EMLA cream should be applied at least 2 hours before harvest of split skin graft for adequate dermal analgesia. ${ }^{[4]}$ Satisfactory dermal analgesia can be achieved after 1 hour of application. It reaches plateau at 2 to 3 hours and lasts for $l$ to
2 hours after removal of cream. Redistribution of the local anaesthetic into the systemic circulation seems to affect the length of analgesia it will provide. Length is most limited for mucous membranes, the face and diseased skin. ${ }^{[9-10]}$

Ohlsen et $\mathrm{al}^{[11]}$ in 1985 conducted the study to evaluate the efficacy of EMLA cream for harvesting of split skin grafts. They concluded that the operation could be completed without supplementary local or general anaesthesia although subjects indicate moderate degree of pain. No systemic side effects were observed.

Lahteenmaki et al ${ }^{[12]}$ in 1988 compared single application versus two successive applications of EMLA for skin grafts. No difference in pain was experienced in both the groups. Goodacre et al ${ }^{[4]}$ in 1988 compared EMLA versus local infiltration for graft harvest. They concluded that patients experienced no pain during EMLA application whereas varying degrees of pain were experienced while injecting local anaesthesia. Both were found to be equally effective in reducing pain during and after the graft harvest which was similar to our study. They final concluded that EMLA can be considered as anaesthesia of choice for graft harvest. K. S. Sahi et al ${ }^{[13]}$ in 2014 conducted study to compare effectiveness of EMLA cream and local infiltration during graft harvest. They found no significant differences between two groups with respect to operating time, intraoperative pain during graft harvest, post-operative pain and need for analgesia. Our results are very similar to this study.

A topically applied EMA is found to be suitable for cutting a split skin graft. It possesses several advantages over the conventional injection of local anaesthetic. No pain is felt by patient during its application as compared to infiltration of local anaesthetic. ${ }^{[4,11]}$

Donor area bleeding was more in EMLA applied patients as it does not contain any vasoactive compound which is present with infiltrated lignocaine. ${ }^{[4]}$ The unique limitation acknowledged comprises the waiting period of $2 \mathrm{hrs}$ after its application. It can be taken care of by applying the cream while the patient is waiting in pre-operative room outside operation theatre. It hinders the apprehension and anxiety of needle pricking as felt during infiltration of an anaesthetic agent.

EMLA cream is equally discovered to be useful in superficial skin surgical procedures like epidermal surgery, dermabrasion, skin biopsy. ${ }^{[14-17]}$ It has also been effective in venepuncture or IV cannula insertion. ${ }^{[18-19]}$ EMLA represents $a$ therapeutic breakthrough for being the first topical anaesthetic preparation which has the ability to penetrate intact skin and provide reliable anaesthesia. ${ }^{[20]}$

Preoperatively application of EMLA cream followed by infiltration of local anaesthesia can also be done. EMLA application will decrease the pain associated with needle injection and local anaesthesia infiltration will decrease the bleeding after graft harvest taking advantages of both the procedures. However, this kind of study is not found in literature. Such kind of study is yet to be conducted to establish its outcome.

\section{CONCLUSION:}

Split skin graft can be easily harvested using topical application of EMLA cream. It is direct to apply and undergoes pain free application with results almost similar to infiltration of local anaesthetics making it a suitable alternative method of anaesthesia for graft harvest. 


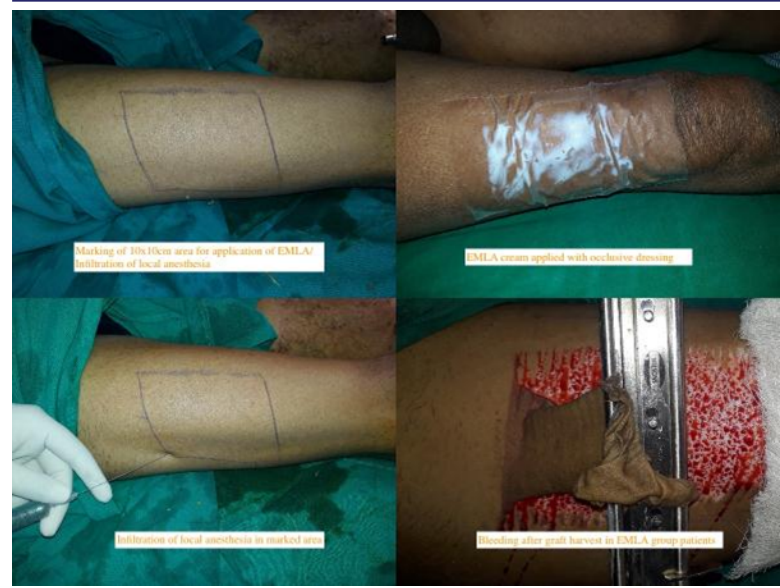

\section{REFERENCES:}

1. J. Small, R. G. Wallace, R. Millar, A. D. Woolfson and D. F. McCafferty. Pain-free cutting of split skin grafts by application of a percutaneous local ancesthetic cream. British journal of plastic surgery 1988;41:539-543.

2. Gajraj NM, Pennant JH, and Watcha MF. Eutectic Mixture of Local Anesthetics (EMLAB) Cream. Anesth Analg 1994;78:574-83

3. Ponten, B. and Ohlen, L. Skin surface application of ketocaine to provide local ancesthesia for cutting split skin grafts. British Journal of Plastic Surgery 1977;30:251.

4. Goodacre TEE, Sanders R, Watts DA, Stoker M. Split skin grafting using topical local ancesthesia (EMLA): A comparison with infiltrated anaesthesia. British Journal of Plastic Surgery 1988;41:533-538.

5. Chapman HR, Kirby-Turner N. Visual / verbal analogue scales: Examples of brief assessment methods to aid management of child and adult patients in clinical practice. Br Dent J 2002;193:447-450.

6. Bjerring P, Andersen P H, Arendt-Nielsen L. Vascular response of human skin after analgesia with EMLA cream. Br. J. Anqesth 1989;63:655-660.

7. Hallen RG. Blocking effects of a topical anesthetic composition containing Ketocaine on cutaneous $\mathrm{C}$ receptor responses in alert man. Acta Anaesthesiol Scand 1974; 18(4):306-17.

8. Georgette Oni, Spencer Brown, Jeffrey Kenkel. Comparison of Five Commonly-Available, Lidocaine-Containing Topical Anesthetics and Their Effect on Serum Levels of Lidocaine and Its Metabolite Monoethylglycinexylidide (MEGX). Aesthetic Surgery Journal 2012;32(4): 495-503.

9. Nielsen JC, Arendt-Nielsen L, Bjerring P, Svensson P. The analgesic effect of EMLA cream on facial skin: quantitative evaluation using argon laser stimulation. Acta Derm Venereol 1992;72:281-284.

10. Arendt-Nielsen L, Bjerring $P$ Nielsen J. Regional variations in analgesic efficacy of EMLA cream: quantitatively evaluated by argon laser stimulation. Acta Derm Venereol 1990;70:314-318.

11. Ohlsen, L., Engiesson, S. and Evers, H. An anaesthetic lidocaine/prilocaine cream (EMLA) for epicutaneous application tested for cutting split skin grafts. Scandinavian Journal of Plastic and Reconstructive Surgery 1985; 19:201.

12. Lahteenmaki T, Lillieborg S, Ohlsen L, Olenius M, Strombeck J O. Topical analgesia for the cutting of split skin grafts: a multicenter comparison of two doses of a lidocaine/prilocaine cream. Plast. Reconstr. Surg 1988;82:458-462.

13. K.S.Sahi, Geeta Bhandari, Bhuvan, Prashant, Sanjeev, Rakesh et al. Split skin graft harvesting under local anesthesia versus topical local anesthesia. Journal of evolution of medical and dental sciences 2014;3(17):4615-4620.

14. Juhlin L, Evers H, Broberg F. A lidocaine-prilocaine cream for superficial skin surgery and painful lesions. Acta Derm Venereol 1980;60:544.

15. Hallen A, Ljunghall $\mathrm{K}$, Wallin J. Topical anaesthesia with local anaesthesia (lidocaine and prilocaine, EMLA) cream for cautery of genital warts. Genitourin. Med 1987;63:316-319.

16. Ljunghall $\mathrm{K}$, Lillieborg $\mathrm{S}$. Local anaesthesia with a lignocaine/prilocaine cream (EMLA) for cautery of condylamata acuminate on the vulval mucosa. The effect of timing of application of cream. Acta. Derma. Venereol. (stockh.) 1989;69:362-365.

17. Rosdahl I, Edmar B, Gilssen H, Nordin P Lillieborg S. Curretage of molluscum contagiosum in children analgesia by topical application of a lidocaine/prilocaine cream (EMLA). Acta. Derma. Venereol. (stockh.) 1988;68:149-153

18. Munshi AK, Hegde AM, Latha R. Use of EMLA: is it an injection free alternative? J Clin Pediatr Dent 2001;25:215-219.

19. Wahlstedt C, Kollberg H, Moller C, Uppfeldt A. Lignocaine-prilocaine cream reduces venepuncture pain. Lancet II 1984:106.

20. Anna Taddio, Arne Ohlsson, Thomas R. Einarson, Bonnie Stevens and Gideon Koren. A Systematic Review of Lidocaine-Prilocaine Cream (EMLA) in the Treatment of Acute Pain in Neonates. Pediatrics feb 1998;101(2). 